\title{
A Study on Effect of Industry Type \& Perception of Power in Distribution Channel Using Randomized Block Design
}

\author{
Kaushik Mandal and Koushick Roy
}

\begin{abstract}
The concept of power is very much essential in the context of distribution channel management. Channel principal uses different power dimensions to control the channel participants for effective and efficient fulfillment of company's overall objective. Literatures talks about six sources of power perception by channel members. Our objective is to evaluate the variation in terms of perceived importance of the various power sources among channel principals. Authors also appreciate the role of industry informing this said variation. Thus authors have planned to block the effect of industry by means of simultaneous measurement of two different factors like effect of variety in perceived importance of various power sources and industry effect on perception of power of channel participants. Authors have employed four industries of varying nature for this study and also employing randomized block design for this purpose. The result explains that perception of power varies with type of industry and due to difference in perceived importance of each power dimension.
\end{abstract}

Index Terms - Channel participants, distribution channel, perception of power, randomized block design.

\section{INTRODUCTORY NOTE}

In modern marketing practice the importance of effective channel control is getting more attention by both academics and practising channel managers. It is essential for marketer for efficient operation of the distribution channel system. Efficient channel management operation leads to fulfilment of company's overall objective. Efficiency in the channel management comes not only by management of physical distribution but also from behavioural management of channel partners. Moreover, proper behavioural management of the channel partners leads to long term relationship with channel participant. To control the channel member's behaviour and to motivate them to act as per the wishes of channel leader, channel principal adopts various ways to influence their behaviour. This ability of influencing of one channel member to other member towards fulfilment of a particular communication is termed as 'power'. The theory of power is essential to understand this channel control mechanism in distribution channel management. Channel principal uses power to control the channel member's behaviour towards attainment of company's overall objective. Based on which channel subordinates (partner) perceive about power sources of the channel principal (marketer). Some of them are in belief for enjoying

Manuscript received April 9, 2012; revised May 15, 2012.

K. Mandal and K. Roy are with Department of Management Studies, National Institute of Technology, M. G. Avenue, Durgapur, Pin: 713209, W.B, India. (e-mail: kaushikmandal.nit@gmail.com). reward by executing what is asked for complying. Alternatively, channel participants may have trust upon channel leader just to use expertise they have. Some of them may be simply abided by the rules and regulations. Some of them are also having trust on information content based on logic and reasoning provided by principal and sometimes they are compelled to obey the instructions. Others may obey the direction with an objective to leverage corporate equity poses by channel principal.

Various management literatures [1] -[5] termed these various forces of influencing the channel member as various power dimensions. These power dimensions are referred as reward, coercive, legitimate, referent, information \& expert Power. Literatures in relation to channel management have always given emphasis on power perception of channel participant on those six dimensions of power. Researchers have also claimed that these six power sources are standard $\&$ universal in nature but practices \& market wise variations of this theory are well understood [6], [7]. Not only channel principal vary the operation of various power bases to control the channel subordinate but also channel subordinates also perceive application of power upon them in a varied way. In fact, they perceive various power facets not as a mutually exclusive rather by a combination of multiple power facets [8], [9]. The source of channel principal's power is grown from their various positive resource factors. The corporate image of the principal, brand equity, innovation, distribution framework, nature of industry, product \& market and expertise etc. are the various issues, which make one channel principal more powerful.

So, for managing the channel member, understanding the effectiveness of different sources of power is important aspect. Thus, considering the above facts, the question, which already arises in our mind, again knocks us to rethink about the evaluation of the variation in power among channel principal relationship. Thus, to converge to a point whether these six power sources are perceived with equal importance by channel participants across the industry or not, we have planned to carry out a systematic investigation. But before exploring the problem, it is also necessary as a part of exploration to review the existing literatures especially any work that is available based on variation in power perception among channel participants.

\section{THEORETICAL BACKGROUND}

'Power' is the concept mostly associated with politics and its related literatures. Simon [10] proposed the measurement of power in political literature. At the same 
time it is not limited to politics, rather it is equally important issue for discussion for any socio-economic studies that is directly or indirectly related with politics. Especially for those socio-economic studies deals with behaviour of the people 'power' can play a vital role. Dahl [11] introduced the essentialities of power related issues in behavioural science. He explained the concept of power in terms of change in behaviour of one in response to others behaviour. However, said concept of power is also relevant for management of channel of distribution. First time, French \& Raven [2] \& Cartwright [12] have employed 'power' concept vis-à-vis behavioural management of channel partners. After that there are several literatures [3]-[5] developed and all these literatures have been developed in the similar line of thought. Detail analysis of the literature helps us to understand that channel partners are having perception about power hold by their channel leader (marketer). It is also revealed from the literature that channel partner perceives five types of power sources held by channel leader (marketer) [2]. Other than French \& Raven [2], Swasy [1] has added one powerbases, called 'information exchange' over the five mentioned by French \& Raven [2]. According to this research of Swasy [1] 'information exchange' dimension is used by the channel leader (marketer) provide strategic information to channel partner, it is obvious that channel partners are dependent to channel leader for these sets of information. Later some other dimension like 'market power of the customer' is suggested by Butaney \& Lawrence [13]for the purpose of understanding perception of channel partner in relation to power sources hold by channel leader (marketer). Literature also talks about coercive and non-coercive power bases [14]. Research result suggests reward, expert, referent, information exchanges are all the non-coercive power and coercive \& legitimate are the example of coercive power bases [14]. Debate is also there in relation to inclusion of legitimate power in either any of the group. Some suggested legitimate as a separate group holding equal distance from both the group coercive $\&$ non-coercive power bases. On the other hand researchers have also provided utmost effort to define power and develop construct for measurement of 'power' [12], [13]. Ansary \& Stern [15] defined the power in terms of ability of channel leader (marketer) to control the behavioural decision making of channel partners. Lush [16] identified a high positive correlation between channel partner's perceived inter channel conflict and use of coercive power by channel leader (marketer). In the similar way he also found a high negative correlation between channel participants perceived inter channel conflict and use of non coercive power bases by the channel superior (marketer). Thus it is very easy to understand that degree of coercion by the channel leader is directly related with channel conflict and vice-versa. Hunt \& Nevin [14] have explored some supportive result for Lush [16]. According to Hunt \& Nevin [14] channel satisfaction is inversely related with employment of non-coercive power by the marketer. There are some good researches on economic perspective of all these power bases. Lush \& Brown [17] detailed out powerbases in two different types i) economic power bases: related to monetary factor \& ii) non economic powerbases: related to other than monetary factor. According to them coercive, reward and legitimate are the three economic powerbases. Because all these three are related to monetary benefit or sanction of the channel partners. On the other hand rest of the power belongs to non economic powerbases because these three reflects different type of controlling to channel partners which are independent of monetary gain or loss. Bacharach \& Lawler [18], Frazier [19] have appraised critically French \& Raven [2] endorsed concept of powerbases. They told this said concept states about instrument of power execution rather than bases for power. Ghaski [6] has also supported this critical appraisal. Moreover he pledged for developing a construct that is based on attitude of the channel participants which is also useful to understand the instrument of power execution.

Research has also been carried out in related field of concept. Frazier \& Summer [7] Kale [8] \& Frazier et. al [9] all these authors have worked on interfaces of influence \& power concept in relation to distribution channel. The most important part of these researches is identification of 'influence' as an application of power perception. Thus they provide the answer to missing link of the literature created after Ghaski's work. Ghaski \& Nevin [20] proposed for a more comprehensive model which exploring the relationship in two way classification between exercised power to unexercised power and coercive to non-coercive strategies. They also identified relationship among all these four classifications, satisfaction of channel partner \& performance of channel partner.

Thus considering the all previous literatures on power perception, it is found that all researchers have considered the various dimensions and its applications. However any one of the researches has not focused on the fact that whether all these power dimensions are of equally important to channel participant or not. Researches also failed to carry out in the subject of industry wise analysis of the stated fact. Therefore, present work is an attempt to unfold the abovementioned facts, which is not focused till date in the channel management literatures.

\section{PROBLEM IDENTIFIED \& HYPOTHESIS DEVELOPED}

Problem which appears are bi-facets in nature. We also believe that these two problems are independent to each other. Because of independence interaction is absent, thus we planned for designing our research in a research design format which is known as 'Randomized Block Design' [21], [22]. Channel participants' perception about power of the channel leader (marketer) is of different types and all these types are whether of different importance or not to channel participants is the basic query for us. We can consider this as first one of the dual problem for the present work. We can hypothesize this problem as follows:

$\mathrm{H}_{0}{ }^{1}$ : There is no difference in term of perceived importance of power sources to the channel participant of the industry studied as a whole.

$\mathrm{H}_{A}{ }^{1}$ : There is difference in term of perceived importance of power sources to the channel participant of the industry studied as a whole.

This problem is having higher degree of error which can be minimised by blocking the effect of moderating variable. 
For the present problem industry is the blocking variable [23]. We can test the first problem with the help of a different industry result and to check whether results are varied across the industry or not. Infact within an industry channel participants are homogenous but between the industries channel participants are heterogeneous. Hence, we have to check whether perception about power sources of channel leader (marketer) by the channel participants are varied or not. We can hypothesize this problem as follows:

\section{$\mathrm{H}_{0}{ }^{2}$ : There is no difference in channel participant's} perception of power across the industry.

$\mathrm{H}_{A}{ }^{2}$ : There is difference in channel participant's perception of power across the industry.

\section{Statistical Design For PRESENT RESEARCH}

Our objective is to find out whether the impact of industry types and perceived importance by channel partners vis-àvis power sources affecting the power perception of the said channel partners or not. Simultaneously when we check two independent factors to measure its effect on dependent variable, we employ two way data analysis. Here, we have considered overall power perception as dependent variable and other two factors (industry type \& perceived importance of power) as independent variable as overall power perception of channel participants is depending on type of industry \& perceived importance of individual power dimension. Now, out of two independent factors we use one factor for the purpose of blocking with an objective to lower the error compared to the situation when this blocking has not been done [24]. Along with this within block random replication of sample unit has been done, we termed the said research design as 'Randomized Block Design' [25]. In case of present research in one hand we employ 'industry' which is one of the independent factors used for the purpose of blocking and as a result of these within a given industry we select sample unit randomly and most equally in number (for detail see sampling section). On the other hand we have taken perceived importance of various power sources as another independent factors as a treatment. We have considered perception of channel partner in terms of overall power hold by channel leader (marketer) as dependent variable. Then it is easy for us to assume following model based on above mentioned dependent \& independent variable where we also assume general effect as constant \& random error effect as another important independent part of the model. Model is follows:

\section{Perception of Power $=$ Effect Due to General Factor + Effect Due to Industry Type + Effect Due to Variation in Impact of Power Type + Effect Due to Error}

In mathematical form the model can also be formulated as below:

$$
\mathbf{Y}_{\mathrm{ij}}=\boldsymbol{\mu}+\boldsymbol{\alpha}_{\mathrm{j}}+\boldsymbol{\beta}_{\mathrm{i}}+\boldsymbol{\epsilon}_{\mathrm{ij}}
$$

Where $\mu, \alpha_{j}$ and $\beta_{\mathrm{i}}$ are constants with $\sum \alpha_{j}=\sum \beta_{i}=\mathbf{0}$ and $€_{\mathrm{ij}}$ are independently normal each with niean zerb and variance $\boldsymbol{\sigma}_{\boldsymbol{e}}^{\mathbf{2}}$.

Where, $\mathbf{Y}_{\mathbf{i j}}=$ individual observation on power perception, $\boldsymbol{\mu}=$ General effect mean, $\boldsymbol{\alpha}_{\mathbf{j}}=\mathrm{j}^{\text {th }}$ power dimension effect, $\beta_{\mathrm{i}}$ $=\mathrm{i}^{\text {th }}$ industry effect, $\boldsymbol{\epsilon}_{\mathrm{ij}}=$ random error or residual.

Where, $i$ can be any type of industry like, pharmaceutical, $\mathrm{B} 2 \mathrm{~B}, \mathrm{FMCG} \&$ cement industries and $j$ are the various power sources like, information, reward, expert, referent, legitimate \& coercive sources of power.

If we interested for measuring any one of the independent factors we can go with 'Completely Randomized Design' but in that case error would be higher than the present situation.

\section{SAMPling \& Survey Details}

We have selected distribution channel of water purifier, cement, pharmaceutical industry and FMCG (fast moving consumer goods) for our study because all these industries are heavily dependent on channel partners for distributing their product but these four industries are varied in terms of degree of competition and number of operating brands in existence. After selecting the industry we have chosen sample units randomly separately from each of the industries. As we know samples are selected from population, so it is necessary to define population for the present work. Population of the present work is defined as dealers (cement) and distributors (for other three industries) of south Bengal. West Bengal is a state which represents multicultural and multi linguistic nature of Indian nation. Within West Bengal other than Kolkata, south Bengal holds the higher ratio of market potential.

Hence all of the stated above justify the selection of south Bengal as a geographical scope of present research. From various sources like yellow pages, business directories \& respective business executives, we have collected 417 valid addresses of dealers and distributors. Among these 417 numbers of dealers and distributors, 53 name \& addresses are from B2B. Due to less number of distributors, we have conducted complete enumeration of the sample. From the cement industry we received 117 number of name of the dealers. As it was not possible to conduct complete enumeration, we have chosen almost two third of the sample randomly with the help of random number table. In case of FMCG also we have chosen two third of valid name \& address (80). Last but not the least for pharmaceutical we have generated a list of 130 numbers of distributors, out of which we have selected $80 \%$ of name $\&$ addresses by employing random number table. Thus the total 317 numbers of channel participants have been chosen. We sent request letter along with visited personally to all of them but only $219(69 \%)$ responded by providing us due time \& appointment to conduct survey. We have used the scale of Swasy [1] to develop our questionnaire. We have translated statement in local language along with English as original language of the questionnaire.

\section{Statistical Results \& ANALYSis}

We have started our operation with six dimensional construct identified by Swasy [1]. Each of these dimensions is a combination of some items (See appendix table no: 3 ). Each of this item is a statement in relation to the power perception of the channel partner. We employed this 
construct to run among selected channel participants and received item wise responses from channel partners for each of industries used for present study. Based on item wise observation, we have calculated the arithmetic mean score of every power dimension under each industry. Table 1 provides the summary of mean score of the each of the power dimension for the channel partners of all four industries.

We have conducted two-way analysis of variance where on one hand we have tested variation of power perception across the industry; on the other hand we have verified the difference of importance if any among the various types of power sources [26].

TABLEI: INDUSTRY WiSE OBSERVATION OF VARIOUS TYPES OF POWER

\begin{tabular}{|l|c|c|c|c|c|c|c|c|}
\hline $\begin{array}{l}\text { Industry Type / } \\
\text { Power Sources }\end{array}$ & Information & Reward & Expert & Referent & Legitimate & Coercive & Total & $\begin{array}{c}\text { Block } \\
\text { Mean }\end{array}$ \\
\hline Cement & 3.91 & 4.1 & 4.08 & 4.13 & 3.79 & 2.6 & 22.61 & 3.77 \\
\hline B2B & 3.8 & 3.59 & 3.76 & 3.75 & 3.5 & 2.36 & 20.76 & 3.46 \\
\hline FMCG & 4.02 & 3.46 & 4.19 & 3.54 & 3.22 & 1.8 & 20.23 & 3.37 \\
\hline Pharma & 4.41 & 3.95 & 4.11 & 3.73 & 3.12 & 2.52 & 21.84 & 3.64 \\
\hline Total & 16.14 & 15.1 & 16.14 & 15.15 & 13.63 & 9.28 & 85.44 & - \\
\hline Treatment Mean & 4.04 & 3.78 & 4.04 & 3.79 & 3.41 & 2.32 & - & - \\
\hline
\end{tabular}

By using the below mentioned basic formula, we have calculated the two-way analysis of variance. This is done by calculating $\mathrm{F}$ ratio for each.

By partitioning total sum of square into block, treatment \& error, we get-

Total Sum of Square $($ TSS $)=$ Treatment (Power Bases) Sum of Square (SST) + Block (Industry Type) Sum of Square (SSB) + Error Sum of Square (SSE)

$\mathrm{SS}_{\text {total }}=\mathrm{SS}_{\text {treatment }}+\mathrm{SS}_{\text {blocks }}+\mathrm{SS}_{\text {error }}$

In our Work, the no. of row (block) $=4 \&$ the no. of column (treatment) $=6$

Grand Total $=85.44($ Row total or column total $)$

The Total Sum of square is calculated as -

$\mathrm{SS}_{\text {total }}(\mathrm{TSS})=\sum_{\boldsymbol{i}} \sum_{\boldsymbol{j}}\left(\boldsymbol{Y}_{\boldsymbol{i} \boldsymbol{j}}-\boldsymbol{Y}_{\mathbf{0 0}}\right)^{\mathbf{2}}$
Where,

$\mathrm{Y}_{\mathrm{ij}}=$ individual observation

$\mathrm{Y}_{00}=$ (mean column total/no. of column) $=$ (mean row total $/$ no. of row $)=($ summation of all observations $/$ no. of observations $)=$ Grand Mean

$=(3.91+4.1+4.08+\ldots \ldots \ldots . .+3.73+3.12+2.52) / 24=\mathbf{3 . 5 6}$

$\mathrm{TSS}=(3.91-3.56)^{2}+(4.1-3.56)^{2}+(4.08-3.56)^{2}+\ldots \ldots \ldots . .+$

$(3.73-3.56)^{2}+(3.12-3.56)^{2}+(2.52-3.56)^{2}=\mathbf{9 . 8 7 5 4}$

The formula for calculating Treatment (Power Bases) Sum of Square (SST) is-

$\mathrm{SS}_{\text {treatment }}(\mathrm{SST})=\boldsymbol{r} \sum_{\boldsymbol{i}}\left(\boldsymbol{Y}_{\boldsymbol{i} \mathbf{0}}-\boldsymbol{Y}_{\mathbf{0 0}}\right)^{\mathbf{2}}$

Therefore, Treatment (Power Bases) Sum of Square (SST):

$=\left\{(4.04-3.56)^{2}+(3.78-3.56)^{2}+(4.04-3.56)^{2}+(3.79-3.56)^{2}+\right.$ $\left.(3.41-3.56)^{2}+(2.32-3.56)^{2}\right\} 4$

\section{$=\mathbf{8 . 4 4 0 3 5}$}

Like SST, SSB can calculated as below-
$\mathrm{SS}_{\text {blocks }}(\mathrm{SSB})=t \Sigma\left(Y_{0 j}-\boldsymbol{Y}_{\mathbf{0 0}}\right)^{2}$

Block (Industry Type) Sum of Square (SSB) $=\{(3.77-$ $\left.3.56)^{2}+(3.46-3.56)^{2}+(3.37-3.56)^{2}+(3.64-3.56)^{2}\right\} 6=$ 0.571633

The error sum of square (SSE) can be calculated as: SSE $=$ TSS-SST-SSB

\section{$=9.8754-8.44035-0.571633=\mathbf{0 . 8 6 3 4 1 7}$}

\section{So, in our work SSE is $\mathbf{0 . 8 6 3 4 1 7}$}

The degrees of freedoms are calculated as below:

For SS treatment (power bases) (SST) degrees of freedom (d.o.f) are equal to $\mathrm{c}-1=(6-1)=5$

For SS blocks (industry type) (SSB) degrees of freedom (d.o.f) are equal to $r-1=(4-1)=3$

For $\mathrm{SS}_{\text {error }}(\mathrm{SSE})$ degrees of freedom (d.o.f) are:

$\mathrm{SS}_{\text {error }}$ d.o.f $=\mathrm{SS}_{\text {total }}$ d.o.f $-\mathrm{SS}_{\text {treatment }}$ d.o.f $-\mathrm{SS}_{\text {blocks }}$ d.o.f

$=(\mathrm{rc}-1)-(\mathrm{r}-1)-(\mathrm{c}-1)$

$=\mathrm{rc}-\mathrm{r}-\mathrm{c}+1$

$=\mathrm{r}(\mathrm{c}-1)-1(\mathrm{c}-1)$

$=(\mathrm{c}-1)(\mathrm{r}-1)$

$=(6-1)(4-1)$

$=15$

Mean Square of Treatment (Power Bases) (MST):

$=\mathrm{SST} /$ Degree of Freedom

$=8.44 / 5=1.68$

Mean Square of Block (Industry Type) (MSB):

$=\mathrm{SSB} /$ Degree of Freedom

$=.5716 / 3=0.19$

Mean Square of Error (MSE):

$=\mathrm{SSE} /$ Degree of Freedom

$=.8634 / 15=0.058$

F ratio of Treatment (Power Bases): $=\mathrm{MST} / \mathrm{MSE}$

$=1.68 / 0.058=29.32$

The Tabulated of $\mathrm{F}$ at $1 \%$ probability significance $(99 \%$ confidence interval) with 5 type of industry \& 15 error of degree of freedom is 4.56 .

We reject the null hypothesis if calculated $F$ value is greater than tabulated value and vice-versa. So, our first null hypothesis is rejected and the alternative hypothesis $\mathrm{H}_{\mathrm{A}}{ }^{1}$ is accepted. So, there is difference in term of perceived importance of power sources among channel participants.

$F$ ratio of Block (Industry Type):

$=\mathrm{MSB} / \mathrm{MSE}$

$=0.19 / 0.058=3.31$

The Tabulated of $\mathrm{F}$ at $1 \%$ probability significance $(99 \%$ confidence interval) with 3 type of industry \& 15 error of degree of freedom is 5.42 .

We have found the calculated value is less than tabulated value. Therefore, our second null hypothesis $\mathrm{H}_{0}{ }^{2}$ is accepted. Hence, we can conclude that industry type has not any impact in overall power perception.

We have also confirmed this statistical analysis with the help of statistical software (See Table no: 2). The software generated result is perfectly matched with our calculation. The software also provides us the probability of significance 
of the various factors. We have selected the criterion for probability of significance of this test is 0.01 . Probability value of less than 0.01 represents that there is an impact between both the factors and dependent variable. In our analysis, we have found the probability value of first hypothesis is less than .01. Thus our first null hypothesis is rejected and the alternative hypothesis $\mathrm{H}_{\mathrm{A}}{ }^{1}$ is accepted. So, there is difference in term of perceived importance of power sources among channel participants. We have also found that the probability values for the factor 'Industry Type' is greater than .01 (See Table no: 2). Therefore, our second null hypothesis $\mathrm{H}_{0}{ }^{2}$ is accepted. Hence, we can conclude that industry type has not any impact in overall power perception.

Hence, we can conclude that perceived importance has an effect on measuring overall power perception. But the second factor 'type of industry' has an insignificant role in determination of power perception in distribution channel. Therefore, we can say that the power dimensions mentioned (by Swasy (1) and French \& Raven [2]) are perceived differently in terms of varied importance of each of power dimensions. In other words, the result explains that perception of power only varies with the difference in importance of various exercised power facets. Hence, we can confirm the generalized power perception model as follows-

Perception of Power $=$ Effect Due to General Factor + No Significant Effect of Industry Type + Effect Due to Variation in Impact of Power Type + Effect Due to Error

TABLE II: RESULT OF ANOVA

\begin{tabular}{lrcrrrrrr}
\multicolumn{7}{c}{ TABLE II: RESULT OF ANOVA } \\
\hline Source & $\begin{array}{c}\text { Type III } \\
\text { Sum of } \\
\text { Squares }\end{array}$ & $\begin{array}{c}\text { Degrees } \\
\text { of } \\
\text { Freedom }\end{array}$ & $\begin{array}{c}\text { Mean } \\
\text { Square }\end{array}$ & \multicolumn{1}{c}{ F } & $\begin{array}{c}\text { F at level } \\
\mathbf{1 \%}\end{array}$ & P Value & $\begin{array}{c}\text { Observed } \\
\text { Power }\end{array}$ \\
\hline Corrected Model & 9.012 & 8 & 1.126 & 19.570 & 4.000 & 0.000 & 1.000 \\
Intercept & 304.166 & 1 & 304.166 & 5284.234 & 8.680 & 0.000 & 1.000 \\
Industry Type & 0.572 & 3 & 0.191 & 3.310 & 5.420 & 0.049 & 0.633 \\
Power Bases & 8.44 & 5 & 1.688 & 29.327 & 4.560 & 0.000 & 1.000 \\
Error & 0.863 & 15 & 0.058 & & & & \\
Total & 314.042 & 24 & & & & & \\
Corrected Total & 9.875 & 23 & & & & & \\
\hline
\end{tabular}

We have also estimated $\mathrm{R}$ square to assess the goodness fit of the model. R square also assists us to know the effectiveness \& reliability of the relationship of various factors for measuring power perception. $\mathrm{R}$ square can be calculated by dividing the sum of squares for the model by the total sum of squares. It represents the amount of variance explained by the model vis-à-vis total variation [27]. R square can calculated as follow-

$$
\begin{aligned}
& \mathrm{R}^{2}=\frac{\text { Explained Variation }}{\text { Total Variation }} \\
& \mathrm{R}^{2}=9.012 / 9.875 \\
& \mathrm{R}^{2}=0.913
\end{aligned}
$$

In our work $\mathrm{R}$ square value is $91.3 \%$ which offers a better predicts of the power perception of distribution channel. This high value of $\mathrm{R}$ square also forecast the issue of goodness of model fit.

We have also estimated the eta - squared $\left(\eta^{2}\right)$ to measure the effect size or strength of association between perception of power and the various factors behind that. Eta -squared $\left(\eta^{2}\right)$ describes the ratio of variance explained in the dependent variable by a predictor while controlling other predictors. The Eta-squared $\left(\eta^{2}\right)$ is calculated by following-

$$
\eta^{2}=\frac{\mathrm{S}_{\text {treatment }}}{\mathrm{S}_{\text {total }}}
$$$$
\mathrm{S}_{\text {total }}=0.572+8.44+0.863=9.875
$$

$\begin{array}{lll}\eta^{2} \text { for industry type } & =0.572 / 9.875 & =0.057 \\ \eta^{2} \text { for power bases } & =8.44 / 9.875 & =0.854 \\ \eta^{2} \text { for error } & =0.863 / 9.875 & =0.087\end{array}$

$\eta^{2}$ for error
Therefore, we have seen industry type explain $6 \%$ variance. Perceived importance of power dimensions shows most $(85 \%)$ of the strengths of association in measuring the overall power perception and error demonstrates only $9 \%$ variance explained.

Thus, the present work demonstrates that perceived importance of power dimensions has a significant function in determining the overall power perception of channel participants, whereas types of industry plays an insignificant contribution in determining the power perception. Therefore the power bases represented by Swasy [6] and French \& Raven [3] are applicable in practice in India. These power dimensions are equally perceived by channel members across the industries. The variation of overall power perception which is taken place in channel management mechanism is only due to the difference in perceived importance of power dimensions. Probably the reason behind this difference in perceived importance of power dimensions is the corporate equity of the marketer, brand equity; innovation, distribution framework and expertise etc.

\section{CONCLUDING REMARKS}

We may start concluding with the model which we have developed during course of our research. Model states that overall 'perception of power' is dependent on independent factor 'variation in perceived importance of power'. Due to variation in perceived importance of power the overall power perception varies positively. If there is more variation in perceived importance of power observed, it would result in high perception of power. But the power perception does not vary for the independent factor 'type of industry'. So, the variation in power is due to only difference in perceived importance of power dimensions. Type of industry has not having any effect over the overall power perception. So the model proposed by Swasy [6] and French \& Raven [3] is standardised in Indian context in nature \& practice across the industries.

However, this model also proposed for effect of construct which we consider as a general effect. That mean without having any impact from the independent variables ignoring the random effect what we get as perception of power which is due to general effect. Random effect is the disturbing factor for the model.

Finally, this proposition is learning for Indian manger to carry out their routine, operational channel management activities. This model helps them to learn the importance of identifying the most important power instrument for their own industry.

\section{REFERENCES}

[1] L. J. S, "Measuring the Bases of Social Power," In William L Willie (Ed), Advances In Consumer Research, vol. 6, pp. 340-346,1979. 
[2] J. R. French and B. Raven, "The basis of social power," In D. Cartwright (Ed), Studies in social power, Ann Arbor. MI: Institute of Social Research, Pp. 150-167, 1959.

[3] D. J. Bowersox, E. W. Smykay, and B. J. Londe, Physical Distribution Management, 2nd ed., Collier-Macmillan, New York, NY, 1968.

[4] L. P. Bucklin, "A Theory of Channel Control," Journal of Marketing, vol. 37, Jan, pp. 39-47, 1973.

[5] A. I. El-Ansary and R. A. Robicheaux , "A Theory of Channel Control: Revisited," Journal Of Marketing, vol. 38, Jan ,pp. 2-7, 1974

[6] J. F. Ghaski, "The Theory of Power and Conflict in Channel of Distribution," Journal of Marketing, vol. 48, summer, pp. 9-29, 1984.

[7] Frazier and J. O. Summers, "Perceptions of Interfirm Power and its use within a franchise channel of distribution," Journal of Marketing Research, vol. 23, May, pp.169-76, 1986

[8] S. H. Kale, "Dealer perceptions of manufacturer power and Influence Strategies in a developing country," Journal of Marketing Research, vol-XXIII, Nov, pp.387-93, 1986

[9] J. G. Fraizer and S. Kale, "Dealer Dependence Levels and Reciprocal Actions in a Channel of Distribution in a Developing Country," Journal of Marketing, vol. 53, January, pp. 50-69, 1989.

[10] S. Herbert, "Notes on the observation and measurement of Power," Journal of politics, vol. 15, Nov, pp. 500-18, 1953.

[11] R. A. Dahl, "The concept of Power," Behavioral Science, vol. 2:3, July, pp. 201, 1957.

[12] D. Cartwright, "A Field Theoretical Conception of Power," In D. Cartwright (ed.) Studies in Social Power (Ann Arbor: Institute for Social Research), 1959

[13] G. Butaney and L. H. Wortzel, "Distributor Power Versus Manufacturer Power: The Customer Role," Journal of Marketing, vol. 52, January, pp. 52-63, 1988

[14] S. D. Hunt and J. R. Nevin, "Power in a channel of distribution: Sources and consequences," Journal of Marketing Research, vol. 11, May, pp. 186-93, 1974

[15] A. I. El-Ansary and W. S. Louis, "Power Management In The Distribution Channel," Journal Of Marketing Research, vol. 9, February, pp. 47-52, 1972.

[16] R. F. Lusch, "Sources of Power: Their Impact on Intrachannel Conflict," Journal of Marketing Research, vol. XIII, Nov, pp. 382-90, 1976.

[17] R. F. Lusch and J. R. Brown, "A Modified Model Of Power In The Marketing Channel," Journal of Marketing Research, vol. 19, August, pp. 312-23, 1982.

[18] S. Bacharach and E. Lawler, Power and politics in Organizations, San Francisco: Jossey-Bass, 1980.

[19] Frazier, "On the Measurement of Interfirm Power in Channel of Distribution," Journal of Marketing Research, vol. 20, May, pp. 15866, 1983.
[20] J. F. Ghaski and J. R. Nevin, "The Differential Effects of Exercised and Unexercised Power Sources in a Marketing Channel," Journal of Marketing Research, vol. 22, May, pp. 130-42, 1985.

[21] S. Addelman, "The Generalized Randomized Block Design," The American Statistician, vol. 23, no. 4, pp. 35-36, Oct. 1969.

[22] T. Caliński and S. Kageyama, Block designs: A Randomization approach, Volume I: Analysis. Lecture Notes in Statistics, 150. New York: Springer-Verlag. ISBN 0-387-98578-6, 2000.

[23] K. Hinkelmann and O. Kempthorne, Design and Analysis of Experiments, I and II (Second ed.). Wiley. ISBN 978-0-470-38551-7, 2008.

[24] D. Raghavarao and L. V. Padgett, Block Designs: Analysis, Combinatorics and Applications, World Scientific. ISBN 9812563601, 2005.

[25] A M, Gupta and B. Dasgupta, Fundamentals of Statistics, World Press, Kolkata, Ninth Ed., 2008

[26] J. F. Hair, W. C. Black, B. J. Babin, R. E. Anderson, and R. L. Tatham, Multivariate Data Analysis, 5th Ed., Pearson Education, New Delhi, India, 2006.

[27] A. Field, Discovering Statistics Using SPSS (3rd Ed.), Sage Publication, 2009.

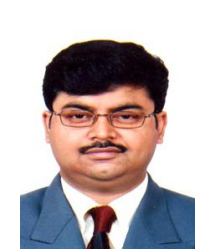

Dr. Kaushik Mandal is Assistant Professor of Marketing in the Department of Management Studies, National Institute of Technology, Durgapur, India. He is holding master and doctoral degree both in marketing area under business administration. $\mathrm{He}$ is having good number of publications in his credit. He has been serving the academics for more than eight years. Prior to teaching Dr. Mandal has worked for industry. Dr. Mandal can be contacted at e-mail: kaushikmandal.nit@gmail.com.

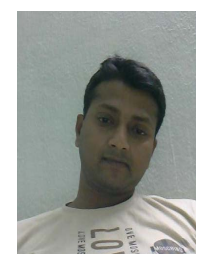

Koushick Roy is an executive in consumer durables industry for last 6 years. He is also associated with Department of management Studies, National Institute of Technology, Durgapur, India as a capacity of part time doctoral student. He has two numbers of publications in his credit. Koushick Roy can be contacted at e-mail: koushickroy@gmail.com. 